\title{
Evaluation of rheological, physicochemical, and sensory properties of apple incorporated yoghurt
}

\author{
Chaitali Chakraborty, Suparna Mukherjee and Srijanee Biswas
}

Received: 05 May 2018 / Accepted: 19 December 2018 / Published online: 21 February 2019

(C) Indian Dairy Association (India) 2019

\begin{abstract}
Yoghurt, one of the fermented milk products, is a functional food which is popular and acceptable by consumers for several years. Yoghurt is a high nutritious food containing $\alpha$ lactalbumin, $\beta$-lacto globulin, vitamin $\mathrm{A}$, calcium and phosphorus. It is used to aid a variety of gastrointestinal disorders. Apples have higher shelf life (1-2months in refrigerator) compared to many other fruits. Apple consist higher amount of fructose (about $12.6 \mathrm{gms})$ that acts as a natural sweetener which decreases the requirement of added sucrose to yoghurt. In this study a settype fruit yoghurt was developed by addition of apple pulp. The physico-chemical, sensory and rheological properties of different types of yoghurt were determined. A control (C) was prepared to compare the quality characteristics with Apple Incorporated Yoghurt. The $\mathrm{pH}$ of the apple incorporated yoghurt lies between 3.89-4.01 whereas for control yoghurt it is between 4.14-4.34. The addition of apple pulp lead to decrease the $\mathrm{pH}$, syneresis percentage, viscosity and an increase in total solid (TS), water holding capacity (WHC) of the yoghurt. AY3 revealed the highest () WHC (\%) whereas the lowest value was observed in case of C. Flow index behavior for $\mathrm{C}, \mathrm{AY} 1, \mathrm{AY} 2$ and $\mathrm{AY} 3$ were found as 0.57 , $0.418,0.402$ and 0.395 respectively. So it can be concluded that
\end{abstract}

\footnotetext{
Chaitali Chakraborty $(\square)$

Department of Dairy Chemistry, Faculty of Dairy Technology, WBUAFS, Mohanpur, Nadia, West Bengal, India

E-mail: ccty09@gmail.com
}

Suparna Mukherjee, Srijanee Biswas

Department of Food Technology,

Guru Nanak Institute of Technology, Panihati, Sodepur, Kolkata, India, apple incorporated yoghurt serves as an excellent food worldwide and can be easily accepted by the consumers.

Keywords: Apple incorporated yoghurt, Physico-chemical analysis, Rheological analysis, Sensory analysis

\section{Introduction}

Yoghurt, which is a commonly fermented dairy product, is obtained from the fermentation of milk by lactic acid-producing bacteria such as Streptococcus thermophillus and Lactobacillus delbrueckii spp. bulgaricus (Fadela et al., 2009). Yoghurt has a variety of probiotics and vitamins and is well received by consumers. Consumption of yoghurt is associated with some health benefits because of the lactic acid bacteria. As there is a lot of sugar and fat in it, it is not suitable for hyperpietics and diabetics. In recent years, consumers' demand for low-fat or nonfat dairy products has increased (Bitaraf et al., 2012).

Yogurt is considered as healthy food due to its high digestibility and bioavailability of nutrients and also can be recommended to the people with lactose intolerance, gastrointestinal disorders such as inflammatory bowel disease and irritable bowel disease, and aids in immune function and weight control (Danone, 2013).Addition of flavors would enhance the consumer appeal while produce a variety of products. Flavors can either be added immediately before homogenization or after the homogenization. Yogurts are available in a vast array of flavors including fruit (apple, apricot, black cherry, black currant, blue berry, lemon, mandarin, raspberry, strawberry, peach), cereal, vegetables, chocolate, vanilla, caramel, ginger, etc (Weerathilake et.al., 2014; Chakraborty et.al., 2017).

\section{Materials and methods}

\section{Fruit pulp preparation}

Mature ripened apples were brought from local market of Sodepur, West Bengal and washed thoroughly. Then the apples were boiled at $90-95^{\circ} \mathrm{C}$ for around $5-10$ minutes. After boiling, the skin, core and seeds of the apples were removed properly. Then 
it was chopped in small cubes and crushed and sieved with Siever (SWECO) of 80 mesh size to extract the apple pulp.

\section{Yoghurt preparation}

Pasteurized cow's milk (milk fat 3.6\%, protein 3.3\%, SNF 8.6\%, pH 6.6-6.7) was brought from local market of Sodepur, West Bengal and boiled till the consistency reaches to $1 / 3 \mathrm{rd}$ of its original volume. Then $2 \%$ of yoghurt (purchased from local Sodepur market, West Bengal manufactured by a reputed dairy industry located in Kolkata) is being mixed thoroughly. The total amount of milk was divided into four parts and the fruit pulp at the rate of $10 \%, 20 \%$ and $30 \%(\mathrm{w} / \mathrm{v})$ were added respectively. Then all the samples were incubated at $37^{\circ} \mathrm{C}$ for $7-8$ hours and stored under refrigerated condition until use. A control sample is prepared in the similar manner without addition of fruit pulp.

\section{Physico-chemical analysis}

All the samples were analyzed for titratable acidity, $\mathrm{pH}$, carbohydrate, and protein, fat, crude fiber, ash content, total solid content by using AOAC (2000) methodology. Degree of syneresis, expressed as proportion of free whey, was measured by a small modification of method used by Al-Kadamany et al., 2003. Water holding capacity (WHC) is the amount of water that a food material can hold within itself. Water holding capacity was determined according to Arslan and Ozel (2012).

\section{Microbiological analysis:}

All the samples were analyzed for various microbial parameters. Total Viable Count (TVC), Total Coliform Count (TCC), Total Fungal Count (TFC) were done according to the standard methods given by Wehr and Frank, 2004.

\section{Rheological characteristics}

The rheological flow properties of shear-thinning materials are most commonly described by a two parameter power law model of the form (Jumah et al., 2001). The rheological properties of all the samples were analyzed by using Brookfield rheometer (Model-DV III Ultra programmable rheometer).

$$
\hat{o}=m \tilde{a}^{n}
$$

Where, $\hat{o}$ is the shear stress, ã is the shear rate; $m$ is the flow consistency index and $n$ is the flow behavior index. This powerlaw model is used in this study to describe the behavior of the curd. The value of $n$ is less than one for pseudo plastic material.

\section{Sensory analysis}

A 9 point hedonic scale $(1=$ lowest desirability, $9=$ highest desirability) is designed to evaluate the sensory characteristics by using ten trained panelists (Lim, 2011).

\section{Statistical analysis}

The data were statically analyzed using statistical tool ANOVA described by Snedecor and Cochran (1967). All the data are normally distributed and expressed as Mean \pm SD (Das, 2008).

\section{Results and discussion}

\section{Comparison of Rheological quality of different types of Apple Incorporated Yoghurts}

Textural characteristics of apple incorporated yoghurt samples were analyzed. The most common sensory attributes relating to yogurt texture are thickness /viscosity, smoothness (opposite to lumpiness, graininess, grittiness), and sliminess (or ropiness). Determination of the yogurt texture usually includes sensory, structure and rheology analysis. The results are shown in Fig. 1 and 2 by plotting shear stress vs shear rate and viscosity vs shear rate. According to the textural analysis, the values of consistency (m) and flow index (n) resulting from the fit of the power law model for different samples can be found in Table 1 . Flow index for $\mathrm{C}, \mathrm{AY} 1, \mathrm{AY} 2$ and $\mathrm{AY} 3$ were found as $0.57,0.418$, 0.402 and 0.395 respectively. The values of $\mathrm{n}$ in all Apple Incorporated Yoghurt samples are less than 1. Therefore it is

Table 1 Fluid flow behavior of different types of apple incorporated yoghurts

\begin{tabular}{llc}
\hline Sample & Flow index $(\mathrm{n})(\mathrm{Mean} \pm \mathrm{SD})$ & Consistency index $(\mathrm{m})(\mathrm{Mean} \pm \mathrm{SD})$ \\
\hline C & $0.57 \pm 0.015$ & $73.97 \pm 0.23$ \\
AY1 & $0.418 \pm 0.016$ & $72.61 \pm 0.28$ \\
AY2 & $0.402 \pm 0.01$ & $50.78 \pm 0.32$ \\
AY3 & $0.395 \pm 0.009$ & $28.97 \pm 0.18$ \\
\hline
\end{tabular}

Mean $\pm \mathrm{SD}, \mathrm{SD}=$ Standard Deviation. $\mathrm{n}=5$, Average of 5 trials

C: Control Yoghurt

AY1: Apple Incorporated Yoghurt@10\%

AY2: Apple Incorporated Yoghurt @ 20\%

AY3: Apple Incorporated Yoghurt @ 30\% 
Fig 1. Flow behavior of different types of apple incorporated yoghurt samples

\section{Flow behaviour of Apple Incorporated Yoghurt}

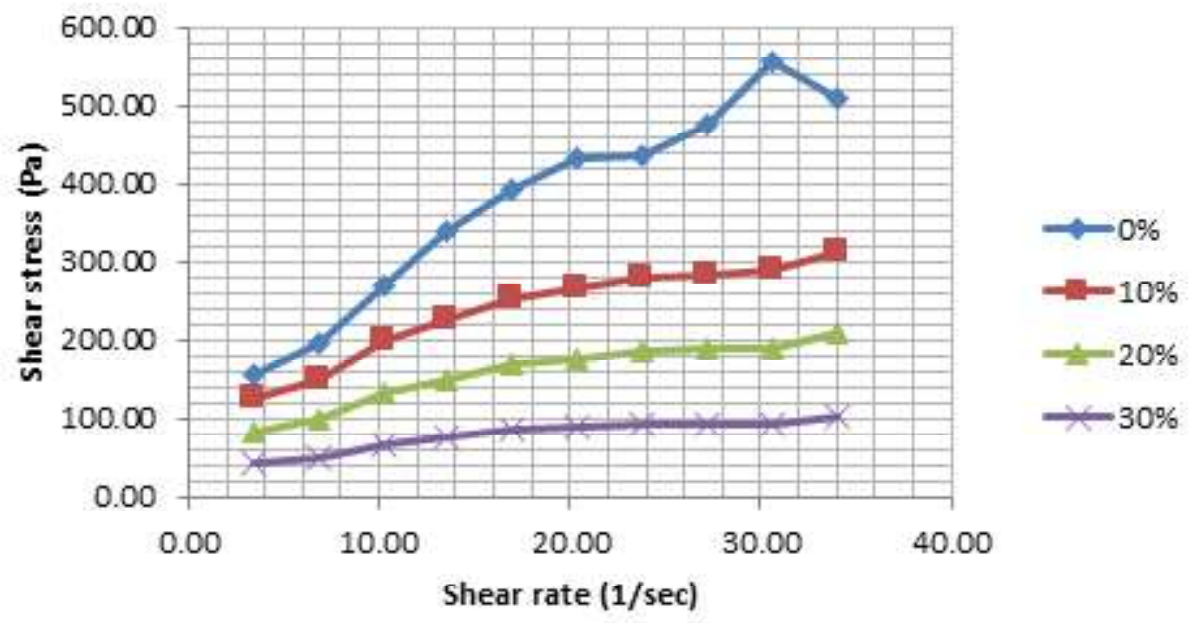

Rheological Analysis of Apple Incorporated Yoghurt

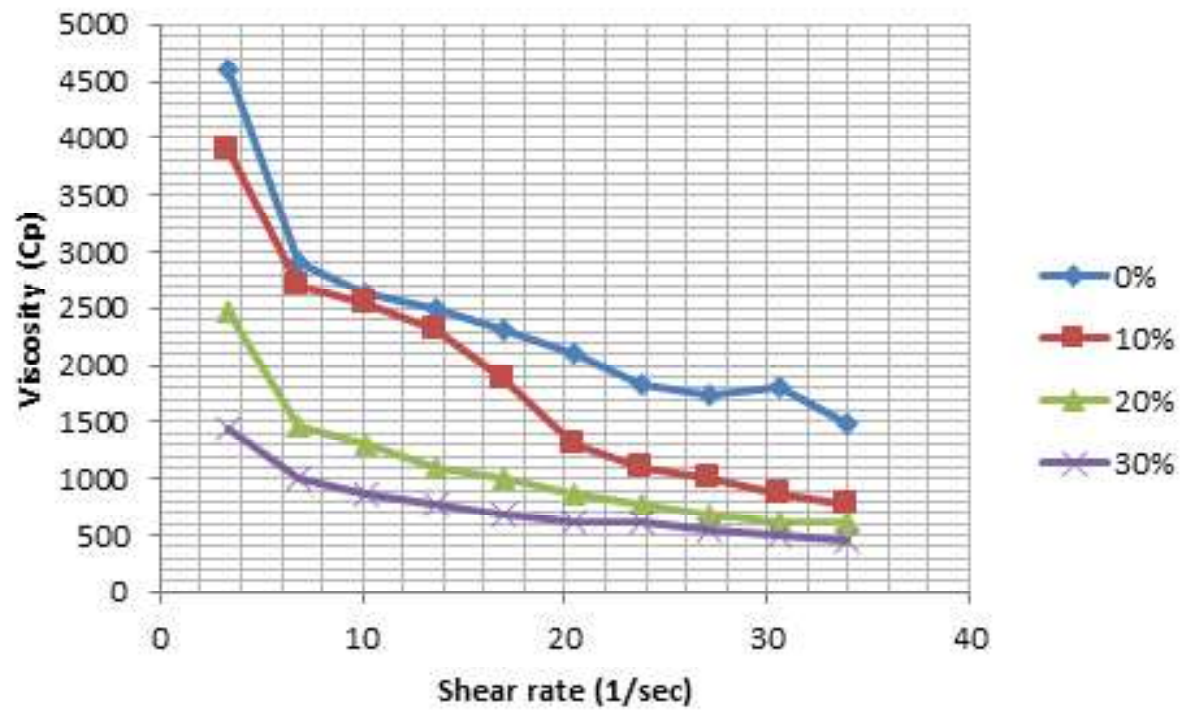

evident that all samples show pseudo-plastic behavior. Dutta et al., 2016 observed similar rheological characteristics (n less than 1) for different types of pineapple curd.

\section{Physico-chemical analysis of different types of Apple Incorporated Yoghurts}

The physico-chemical analysis of different samples of apple incorporated yoghurt is given in table 2. The results revealed that, Apple Incorporated Yoghurt has a lesser $\mathrm{pH}$ than control yoghurt. This is due to the fortification of apple pulp to the yoghurt. Due to the presence of malic acid, apple has a $\mathrm{pH}$ of 3.33.9; control has a $\mathrm{pH}$ of 4-5. So the resultant apple incorportaed yoghurt has a lower $\mathrm{pH}$, so it is more acidic. The acidity of apple incorporated yoghurt is increased for AY3 i.e. 1.31\% LA than the control yoghurt $1.092 \%$ LA. Chakraborty et. al.,2017 reported $0.86 \%$ LA for coffee yoghurt and $1.04 \%$ LA for control Yoghurt.

The syneresis of Apple Incorporated Yoghurt and control are given in table 3. Degree of syneresis is expressed as proportion of free whey. Higher level of syneresis shows that yogurt is of low quality (Aprodu et al., 2012). This study revealed that the syneresis of control yogurt was $59.41 \%$ which was greater than the syneresis of Apple Incorporated Yoghurt. For AY1, AY2 and AY3 syneresis were $46.01 \%, 38.08 \%$ and $25.24 \%$ respectively 
Table 2 Physico-chemical analysis of different types of apple incorporated yoghurts

\begin{tabular}{lllllllll}
\hline Sample & $\begin{array}{l}\text { Acidity) } \\
\text { pH }\end{array}$ & $\mathrm{pH}$ & \multicolumn{2}{c}{ Total solid (\%)Carbohydrate(\%)Protein (\%)Fat (\%) } & \multicolumn{2}{c}{ Crude fiber (\%) Ash(\%) } \\
& (Mean \pm SD & (Mean \pm SD) & (Mean \pm SD) & (Mean \pm SD) & (Mean \pm SD) & (Mean \pm SD) & (Mean \pm SD) \\
\hline C & $1.092 \pm 0.04$ & $4.54 \pm 0.5$ & $17.48 \pm 0.56$ & $9.96 \pm 025$ & $3.44 \pm 0.44$ & $2.92 \pm 0.14$ & - & $0.66 \pm 0.005$ \\
AY1 & $1.12 \pm 0.15$ & $4.19 \pm 0.65$ & $22.57 \pm 0.6$ & $12.99 \pm 0.36$ & $3.92 \pm 0.29$ & $2.81 \pm 0.12$ & $0.12 \pm 0.04$ & $0.74 \pm 0.002$ \\
AY2 & $1.25 \pm 0.1$ & $4.08 \pm 0.40$ & $25.96 \pm 0.38$ & $16.81 \pm 0.24$ & $4.24 \pm 0.14$ & $2.62 \pm 0.42$ & $0.16 \pm 0.01$ & $0.79 \pm 0.005$ \\
AY3 & $1.31 \pm 0.098$ & $4.01 \pm 0.32$ & $27.31 \pm 0.21$ & $19.72 \pm 0.43$ & $4.48 \pm 0.18$ & $2.55 \pm 0.31$ & $0.19 \pm 0.05$ & $0.86 \pm 0.004$ \\
\hline
\end{tabular}

Mean $\pm \mathrm{SD}, \mathrm{SD}=\mathrm{Standard}$ Deviation. $\mathrm{n}=5$, Average of 5 trials

C: Control Yoghurt

AY1: Apple Incorporated Yoghurt @ 10\%

AY2: Apple Incorporated Yoghurt @ 20\%

AY3: Apple Incorporated Yoghurt @30\%

Table 3 Syneresis and Water Holding Capacity (WHC) of different types of apple incoporated yoghurts

\begin{tabular}{lll}
\hline Sample & Syneresis $(\%)$ & WHC $(\%)$ \\
\hline C & $59.41 \pm 0.14$ & $27.56 \pm 0.32$ \\
AY1 & $46.01 \pm 0.60$ & $32.68 \pm 0.26$ \\
AY2 & $38.08 \pm 0.38$ & $41.52 \pm 0.18$ \\
AY3 & $25.24 \pm 0.24$ & $49.25 \pm 0.12$ \\
\hline
\end{tabular}

Mean $\pm \mathrm{SD}, \mathrm{SD}=$ Standard Deviation. $\mathrm{n}=5$, Average of 5 trials

C: Control Yoghurt

AY1: Apple Incorporated Yoghurt@10\%

AY2: Apple Incorporated Yoghurt @, 20\%

AY3: Apple Incorporated Yoghurt @ 30\%

Table 4 sensory analysis of different types of apple incorporated yogurt

\begin{tabular}{llllll}
\hline Parameters & $\begin{array}{l}\mathrm{C} \\
(\mathrm{Mean} \pm \mathrm{SD})\end{array}$ & $\begin{array}{l}\mathrm{AY} 1 \\
(\mathrm{Mean} \pm \mathrm{SD})\end{array}$ & $\begin{array}{l}\text { AY2 } \\
(\mathrm{Mean} \pm \mathrm{SD})\end{array}$ & $\begin{array}{l}\text { AY3 } \\
(\mathrm{Mean} \pm \mathrm{SD})\end{array}$ & Level of Significance \\
\hline Appearance & $7.2 \pm 0.68$ & $8.1 \pm 0.32$ & $8.8 \pm 0.66$ & $7.5 \pm 0.11$ & $* *$ \\
Colour & $7.8 \pm 0.54$ & $7.5 \pm 0.29$ & $8.2 \pm 0.24$ & $8.5 \pm 0.57$ & $* *$ \\
Flavour & $8.5 \pm 0.35$ & $8.2 \pm 0.52$ & $8.7 \pm 0.12$ & $8.7 \pm 0.26$ & $* *$ \\
Body and texture & $8.1 \pm 0.38$ & $7.9 \pm 0.45$ & $8.2 \pm 0.25$ & $8.1 \pm 0.36$ & $\mathrm{NS}$ \\
Mouth feelness & $8.2 \pm 0.28$ & $8.4 \pm 0.22$ & $8.7 \pm 0.35$ & $7.8 \pm 0.28$ & $* *$ \\
Overall acceptance & $8.2 \pm 0.28$ & $8.1 \pm 0.14$ & $8.5 \pm 0.24$ & $8.2 \pm 0.35$ & $\mathrm{NS}$ \\
\hline
\end{tabular}

Mean $\pm \mathrm{SD}, \mathrm{SD}=$ Standard Deviation. $\mathrm{n}=5$, Average of 5 trials

** Significant at $1 \%$ level, NS $=$ Non Significant

C: Control Yoghurt

AY1: Apple Incorporated Yoghurt @ 10\%

AY2: Apple Incorporated Yoghurt @ 20\%

AY3: Apple Incorporated Yoghurt @30\%

(Table 3). Chakraborty et.al., 2017 found $58.06 \%$ syneresis in Control yoghurt and $21.6 \%$ syneresis in coffee yoghurt.

Water holding capacity (WHC\%) is inversely proportional to the syneresis value because when water holding capacity of food increases, it tends to hold more water within itself thus the removal of water through syneresis decreases. From table 3 it is evident that due to the increase in addition of apple pulp in preparing samples, the \%TS value increases and so that WHC \%. Highest value is observed in case of AY3 (49.25\%) and lowest value is observed for control yoghurt (C) $(27.56 \%)$. Similar results were observed by Ara et al., 2015. 
Table 5 Microbiological quality of apple incorporated yoghurt

\begin{tabular}{llllc}
\hline Parameters & Control $(\mathrm{C})$ & AY1 & AY2 & AY3 \\
\hline TVC (log CFU g-1) & 2.08 & 2.41 & 2.86 & 3.50 \\
TCC (CFU g-1) & 0 & 0 & 0 & 0 \\
TFC(CFU g-1) & 0 & 0 & 0 & 0 \\
\hline
\end{tabular}

C: Control Yoghurt

AY1: Apple Incorporated Yoghurt @ 10\%

AY2: Apple Incorporated Yoghurt @, 20\%

AY3: Apple Incorporated Yoghurt @ 30\%

Carbohydrate from fruits provides immediate energy on consumption of the fruits. Hence, supplementations of yoghurt with fruits will not only improve its acceptability (flavour) but also it improve over all nutritional and therapeutic values (Khedar et al., 2015). According to table 2 , highest value was observed in case of AY3 (19.72\%) and lowest for control (9.96\%). Thus with increase in pulp concentration, percentage of carbohydrate increases. The maximum fat content was observed in sample $\mathrm{C}$ (2.92) and minimum in sample AY3 (2.55). This result is in agreement with the findings of Ara et al., 2015. There is an increase of protein content with increase of apple pulp concentration. Thus sample C, AY1, AY2, AY3 has 3.44\%, 3.92\%, 4.24\%, 4.48\% protein respectively. Similar results were found by Matter et al., 2016.There is no added fiber in the sample C. so it has no crude fiber content. Maximum crude fiber percentage was obtained in sample AY3 (0.19\%). Similar results were found by Matter et al., 2016. With increase in apple pulp concentration, ash content increases. Ash content was minimum for sample C $(0.66 \%)$ and maximum for sample AY3 $(0.86 \%)$. Similar results were found by Matter et al., 2016.

\section{Comparison of Sensory quality of different types of apple incorporated yoghurts}

The sensory score and comparison for the parameters of different types of apple incorporated yoghurts are given in Table 4 . Average overall acceptability score of prepared yoghurt samples were found to be 8.2, 8.1, 8.5 and 8.2 respectively. Highest score was recorded for sample AY2 (20\%). The samples had significant influence on appearance, color, and flavor and mouthfeelness.

\section{Microbiological analysis of different types of apple incorporated Yoghurts}

Microbiological characteristics are indicators of safety, quality and shelf life of yoghurt. Total Viable Count (TVC), Total Coliform Count (TCC) and Total Fungal Count (TFC) of the Apple Incorporated Yoghurt samples were determined. Results obtained are shown in Table 5. Highest total viable organism at 0 day (log $\mathrm{CFU} / \mathrm{g}$ ) was recorded for sample AY3 (3.50) and the lowest value was recorded for control sample (2.08). TCC and TFC were nil in all the samples. Similar result was observed by Dutta et al. (2016).

\section{Conclusions}

The demand for gluten free, low fat, diabetes friendly food items are gradually increasing. Apple and yoghurt complements one another. Yoghurt contains certain nutrients absent in apple whereas apples are filled with fibers and Vitamin $\mathrm{C}$ that yoghurt lacks. The production of Apple Incorporated Yoghurt increases market options. Moreover Apple Incorporated Yoghurt serves as an excellent food for children as yoghurt is rich in calcium and vitamin B12, which benefits in building bones. This new product will help dairy industries to enrich the production of commercial yoghurt with enhanced health beneficial properties.

\section{References}

AOAC (2000). Official methods of analysis $17^{\text {th }}$ edition, The association of official and analytical chemistry, USA

Aprodu I, Cerasela EM, Iuliana B (2012). Effect of Transglutaminase Treatment On Skimmed Yogurt Properties The Annals of the University Dunarea de Jos of Galat Fascicle VI - Food Technology $36:$ (2) 20-30

Ara A, Jasim Uddin M, Saha S, Khan MH, Baset MA (2015) Intervention of Fruit Juice in Yoghurt Preparation. Isesco Journal of Science and Technology 11(19):30-35

Arslan, S and Ozel S (2012). Some properties of stirred yoghurt made with processed grape seed powder, carrot juice or a mixture of grape seed powder and carrot juice. Milchwissenschaft 67:281-285

Bitaraf MS, Khodaiyan F, Mohammadifar MA, Mousavi SM (2012) Application of response surface methodology to improve fermentation time and rheological properties of probiotic yogurt containing Lactobacillus reuteri. Food Bioprocess Technol 5:13941401

Chakraborty C, Bandyopadhyay K, Ganguly S, Sarkar U, Das S (2017) Evaluation of rheological, physicochemical and sensory properties of low calorie coffee yogurt, The Pharma Innovation 6(7): 106109

Das NG (2008). Statistical Methods, Combined Edition (Volumes I and II). Tata McGraw- Hill Publishing Company Limited, New Delhi

Dello Staffoloa M, Bertolaa N, Martinoa, M and Bevilacqua A (2004) Influence of dietary fiber addition on sensory and rheological properties of yoghurt. International Dairy Journal 14(3):263-268

Dutta P, Adhikary S, Chakraborty C, Bandyopadhyay K, Paul A and Ray S (2016). Development and characterization of curd fortified by pineapple juice. Indian Journal of Dairy Science 69 (5):524-528

Danone (2013) A brief history of yogurt. [online] Available at: [Accessed 2 December 2013]. 
Foegeding EA, Daubert CR, Drake MA, Essick G, Trulsson M and Vinyard CJ (2011) A comprehensive approach to understanding textural properties of semi- and soft-solid foods. J Texture Stu 42: 103-129

Fadela C, Abderrahim C, Ahmed B (2009) Physico-chemical and Rheological properties of yoghurt manufactured with ewe's milk and skim milk. Department of biology, University of Mostaganem

Jumah RY, Shaker RR, Abu-Jdayil B (2001) Effect of milk source on the rheological properties of yogurt during the gelation process. International Journal of Dairy Technology 54(3): 89-93

Khedkar JN, Choudhari DM, Pawar BK, Vadam VS (2015) Development of fruit based yoghurt. Research Journal of Animal Husbandry and Dairy Science 6 (1): 72-75

Lee WJ, Lucey JA (2010) Formation and physical properties of yogurt, Asian-Aust J Anim Sci 23: 1127-1136
Lim J (2011) Hedonic scaling: A review of methods and theory. Food Quality and Preference 22:733-747

Manjula K, Viswanath C, Suneetha C (2010) Physico-Chemical, Sensory and Microbial Quality of Yoghurt Fortified with Sapota Pulp. International Journal of Material Sciences and Chemistry 1(1):004006

Mathias, TRS, Carvalho Junior IC, Carvalho CWP, Sérvulo, EFC (2011) Rheological characterization of coffee-flavored yogurt with different types of thickener. Alim Nutr Araraquara 22(4):521-529

Matter AA, Mahmoud EAM, Zidan NS (2016) Fruit Flavored Yoghurt: Chemical, Functional and Rheological Properties 2(5):57-66

Weerathilake WADV, Rasika DMD, Ruwanmali JKU, Munasinghe MADD (2014). The evolution, processing, varieties and health benefits of yogurt. International Journal of Scientific and Research Publications 4(4):1-10 